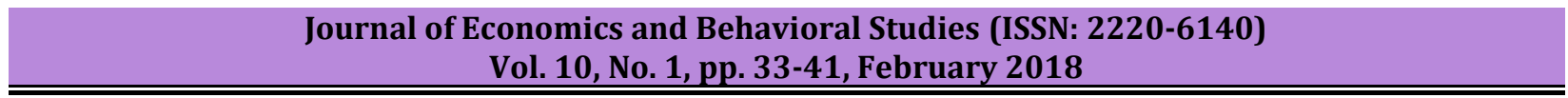

\title{
The Impact of Policy Uncertainty on Macro-Economy of Developed and Developing Countries
}

\author{
Seabelo T. Nyawo ${ }^{1}$, Roscoe Bertrum van Wyk ${ }^{2}$ \\ ${ }_{1}^{1}$ University of Pretoria, Pretoria, South Africa \\ 2University of Stellenbosch Business School, Stellenbosch University, South Africa \\ nyawosabelo7@gmail.com,roscoevanwyk@gmail.com
}

\begin{abstract}
This paper investigates the effects of a US economic policy uncertainty shock on Indian macroeconomic variables with a number of Structural VARs. This study models the economic policy uncertainty index as constructed by Baker et al. (2013). The study also uses a set of macroeconomic variables for India such as inflation, industrial production and nominal interest rate. The objective of the study is to identify the potential impacts of economic policy uncertainty shocks from the US economy to the Indian economy. According to the SVARs, a one standard deviation shock to the US economic policy uncertainty leads to a statistically significant decline in the Indian industrial production of $-0.294 \%$ and in the Indian inflation of $-0.032 \%$. India shows to be resistant to US policy uncertainty. Furthermore, the study finds that the contribution of the US economic policy uncertainty on the Indian macroeconomic variables is shown to be significantly larger than the one exerted by the Indian uncertainty shock.
\end{abstract}

Keywords: Economic Policy Uncertainty, Structural Vector Auto-regressions, US-Indian area spillovers

\section{Introduction}

The role of policy uncertainty has emerged in much of the recent economic debate in the world. It is seen to have important implications for business confidence and the investment climate. The issue of uncertainty in an economy and its consequences has had a long and distinguished recognition in the history of economic thought and policy. If outcomes occur with a probability that cannot even be estimated, the decision-maker, be it from the private or public sector, faces uncertainty. Policy uncertainty plays an important role in the policy discussion. It is prevalent to find an explicit reference to upside and downside risks to the outlook of international and national institutions. The latter takes complex policy decisions into consideration in an environment in which uncertainty about the future state of the economy can never be ruled out. Given the potentially far-reaching relevance of policy uncertainty for the future course of the economy, it is not surprising that considerable attention has been dedicated in the economic literature to characterize the effects of uncertainty on the economy. During the 2008/09 recession and financial crisis, uncertainty about growth in the United States (US) and Europe has been a key concern for policymakers. This study aims to identify the potential impacts of economic policy uncertainty shocks from the US economy to the Indian economy. The US has been selected as the developed country and India as the developing country for this study. This study investigates whether there are any effects of economic policy uncertainty on real economic activity and if so, how large is the impact of the policy uncertainty shock. The VAR model is used in this study, which includes macroeconomic variables for the US and India. The paper mainly focuses on how the effects of economic policy uncertainty has on the economic growth of the Indian economy. The study is in line with recent research that focuses on the impacts of policy uncertainty shocks on the macro economy. This paper follows the direction of Colombo (2013) and utlisesa similar methodology. However, instead of using other macroeconomic variables for the US, the policy uncertainty is utilised in order to explicitly illustrate how this uncertainty shock affects the Indian macroeconomic variables. The uncertainty shock utilised, was developed by Baker et al. (2013), the economic policy uncertainty index. Any unexpected political crisis, an act of terror or financial turmoil prompts the number of articles which deal with the economy and uncertainty to instantly rise (Doms and Moris, 2004). Thereby, providing a correct account of swings in anxiety felt by consumers and investors (Doms and Moris, 2004). It is for this reason that the newspaper coverage index is referred to as the measure of uncertainty.

\section{Literature Review}

The perception of uncertainty about the state of the economy among consumers and investors can hamper economic recovery and growth (Sum, 2012). Both consumers and investors become resistant towards spending and investing when they perceive higher uncertainty in the economy. High levels of uncertainty will 
offer firms a stimulus to freeze investments and hiring of new workers (Bernanke, 1983). Consequently, when firms postpone their levels of investment and hiring, a recession becomes more evident when the economy contracts. According to Sum (2012), the cost of financing is also associated with high uncertainty. A higher level of uncertainty tends to push up the cost of financing (Gilchrist et al., 2010), which will thus lead to lower levels of investment and a decline in the economy (Fernandez-Villaverde et al., 2012). Baker et al. (2013) took a stance that uncertainty about future taxes, spending levels, regulations, health-care reform and interest rates will force firms and consumers to postpone spending on investment and the consumption of goods. The latter links with an earlier study by Rodrik (1991) which shows that the postponement of firms to invest is associated with uncertainty. Higher monetary policy uncertainty tends to cause a greater interest rate to spread which implies a higher dispersion of inflation. For instance, if the rate at which bonds gain value due to movements in inflation, increases on average with the level of uncertainty (Mumtaz \& Zanetti, 2012). Nominal interest rates decrease in response to an increase in the volatility of monetary policy. Mumtaz and Zanetti (2012) further state that if the monetary authority follows the Taylor Rule, the fall in the interest rate must be associated with a decrease in either inflation, productivity or even both. An increase in monetary policy uncertainty causes interest rates, inflation and output growth to fall. According to Bloom (2013), uncertainty does not only decrease the level of investment and staff hiring but it also forces firms to become less sensitive to business conditions factors such as productivity, demand and prices. However, this will lead to high uncertainty which then reduces the impact of stimulus policies such as interest rates and tax cuts. High uncertainty will then cause monetary and fiscal stabilization instruments to become less effective. As a result, Julio and Yook (2012) found that there is a negative relationship between policy uncertainty and investment.

The damaging impact of economic policy uncertainty on growth has been well studied. In recent years the study of this phenomenon globally has led to the new measures of economic policy uncertainty in countries such as the US, United Kingdom (UK), Japan, China and India. As a result, Baker et al. (2013) extensively developed a measure of this distinct kind of uncertainty, as they refer to it as the economic policy uncertainty index. They construct their index by combining different types of components which are proxied by a newspaper coverage. According to Baker et al. (2013), the proxy is nothing more than a representation of the degree of uncertainty felt by households, firms, consumers and producers. In this paper, this index is extensively utilised. Baker et al. (2013) state that their index shows an increase in the economic policy uncertainty around major elections, wars and the 9/11 terror attacks. Bloom (2013) argues that jumps in uncertainty in response to major economic or political shocks, such as the collapse of the Lehman Brothers, leads to a quick decrease and a rapid rebound in productivity and employment. However, policy uncertainty could be high due to the general economic activity also being high. Recent policy uncertainty has emerged from the US debt ceiling dispute and the Eurozone crisis. The macroeconomic effects of uncertainty has been the focus of existing literature (Bloom, 2009; Alexopoulos and Cohen, 2009; Leduc and Liu, 2013; Baker et al., 2013 and Colombo, 2013. All utilising numerous VARs at a macroeconomic level to measure the impact of the uncertainty shocks. Colombo (2013) extensively analyzed the response of a number of macroeconomic factors towards such a shock to a level of uncertainty which affects the economy of the US. Shocks which impact a developed country such as the US is more likely to trigger a reaction to a developing country such as India.

The role that the US uncertainty shock had on the European macroeconomic variable is quantitatively greater than the one invoked by a euro-area specific shock (Colombo, 2013). Many authors consider the harmful effects of monetary, fiscal and regulatory policy uncertainty on economic growth (Friedman, 1968; Rodrik, 1991; Higgs, 1997; and Colombo, 2013). Balcilar et al. (2016) find that economic policy uncertainty in the US collaborates with the influence of monetary policy in Europe. Policy uncertainty regarding any change in policy in the US tends to dampen the effect of monetary policy shocks, coupled with price and output which react more significantly to monetary policy shocks, should the level of US policy uncertainty be at its lowest (Balcilar et al., 2016). However, they show that the government's actions with regards to changes in policy are a source of uncertainty for the European investors. All the high levels of policy uncertainty that trigger a reaction to Europe then drive the euro investors to adopt a wait-and-see approach which leads to a weaker and insignificant response of price and productivity to monetary tightening in the euro area (Balcilar et al., 2016). This follows from the previous literature of Bernanke (1983) and Ramey et al. (2001). In an environment of heightened uncertainty, policymakers might need to implement a strong policy rate cuts or 
tax cuts so as to be able to successfully stimulate the economy (Bloom, 2013). While it is widely believed that variations in uncertainty can have real effects on the economy, estimating empirically such effects is far from being superficial (Berlin, 2016). This is due to the endogeneity problem. In fact, while on the one hand uncertainty generates effects on the economy, on the other hand, economic development affect uncertainty (Berlin, 2016). In order to address this endogeneity problem, the literature typically starts from vector autoregressive models that include several possible variables. These typically are a measure of uncertainty, several proxies for economic activity and a measure of monetary policy intervention. In this paper, the latter method is utilized, which is discussed further in the following section. For further research, a financial variable could be added in order to control for financial development that potentially reflects the evolution of uncertainty. "Why does uncertainty vary?" Bloom (2013) poses this question and answers that there are two mechanisms that drive changes in uncertainty over a period of time.

Firstly, as it has been established, uncertainty shocks that often cause recessions such as wars, oil price jumps and financial consternations appear to directly increase uncertainty. Secondly, uncertainty appears to endogenously rise during recessions, as the economic slowdowns tend to increase both micro and macro volatility. It is widely believed that high uncertainty is detrimental for short-run growth, reducing firms' willingness to hire and invest and consumers' willingness to spend (Bloom, 2009). There are theories which predict the opposite: Bar-Ban and Strange (1996); Alexopoulos and Cohen (2009); Bloom (2013) and Berlin (2016) state there are some positive effects of uncertainty: uncertainty can stimulate research and development. When firms are faced with high levels of uncertainty about the future, they are willing to become more innovative. This effect is usually referred to as the growth option effects. For instance, while the development of internet raised uncertainty as it was a brand new technology, the upside potential was perceived as unbound which as a result led to higher investment in the new technology. Economic uncertainty can be linked to the stock market performance (Bansol et al., 2004). The financial market is a victim of economic policy uncertainty, and not entirely a fan of uncertainty (Sum, 2012). Favero and Giavazzi (2012) and Ehrman and Fratzcher (2009) focus on the spillover effects in the financial markets. The shortfall, however, is that such an indicator may fail to capture the full impact of uncertainty shocks on a broader economy. A paper by Kim (2001) quantifies the role that the US macroeconomic shock stimulates business cycles internationally. There are a few studies that focus on the uncertainty shock arising from the US to other economies. This paper is set up to investigate the impact of these uncertainty shocks to the economy of India. This paper seeks to contribute to a further understanding of the role of the US uncertainty shock and how it triggers a reaction tothe Indian macroeconomic variables.

\section{Methodology}

Data: This study aims to estimate how economic US policy uncertainty shocks impact the Indian macroeconomic variables. The study uses monthly macroeconomic data which spans the period from 2003to 2015. This period is chosen specifically due to the availability of data for economic policy uncertainty index which starts from the beginning of 2003. In order to observe economic policy uncertainty in India and the US, this paper will use two country-specific. There are three components that the policy-related economic uncertainty for the US relies on: i) a news-based component quantifying newspaper coverage on economic policy uncertainty; ii) a measure of the Federal tax code provisions and iii) a measure of disagreement among forecasters. On the other hand, the policy-related economic policy uncertainty for India relies on two components: i) a news-based component and ii) a measure of disagreement among forecasters. According to Colombo (2013), since the economic policy uncertainty indices rely on a different number of components, the paper then focuses on uncertainty indices which are solely based on the news coverage. Included in the vector $Y t$ (which will be discussed in the next sub-section) the news-based components NewsUS and NewsIND as proxies for economic policy uncertainty for the US and India respectively. For the Indian economy the following macroeconomic variables were used:

- Consumer Price Inflation (CPI), as a measure of inflation;

- Industrial Production Index (IPI), as a proxy for the business cycle and

- Nominal interest rate $(i)$, as a proxy for the monetary policy instrument.

All variables are in a logarithmic form, excluding the nominal interest rate and economic policy uncertainty which are represented in a level form. The reason why other macroeconomic variables are in a log-level form 
is that they provide reliable estimates of the impulse responses (Sims et al., 1990). The macroeconomic data used has been retrieved from Easy Data: Data by Quantec. The economic policy uncertainty index is obtained from the "Economic Policy Uncertainty" from [www.policyuncertainty.com].

Methodology: The study analyses the transmission of an uncertainty shock from the US economy to the Indian economy within a two-country Structural Vector Autoregressive model (SVAR). The SVAR model is employed because it treats all the variables in the system as being endogenous. Also, the use of SVAR allows the explicit modeling of contemporaneous interdependence between the left-hand side variables (Pfaff, 2008). Since the nominal interest rate is a proxy for monetary policy, the use of SVAR will assist in identifying the potential shocks which are likely to arise from monetary policy shocks. Most importantly, SVARs are considered good for short-term forecasting. A vector autoregressive equation, such as the one below in (1), is employed to explore the impulse response function of the changes in economic policy uncertainty.

The model that the SVAR renders is as follows:

$B O Y t=(K) Y t-q+\varepsilon t$.

Where: $(K)$ represents the autoregressive lag-polynomia and

etrepresents the structural innovation

Then a vector of the following is assembled:

$Y t=[$ NewsUSCPIINDIPIINDiINDNewsIND $]$

The vector in (2) includes all endogenous variables as defined in the previous sub-section. $Y t$ depends on two blocks: the first block Colombo (2013) refers to it as the foreign variables for the US and the second block the domestic variables for India. As this paper follows Colombo (2013), in this regard a different stance is taken. The foreign variables block is changed and focus only on the NewsUS variable instead of the CPIUS, IPIUSand $i U S$ as Colombo (2013) does.

In order to explain the structure of the economy, the structural shock $\varepsilon t$ is regained from (1) from:

$\varepsilon t=B 0 \mu t$

The variable $B 0$ in (3) consists of the contemporaneous correlations between the structural shocks and reduced form. In order to identify $B 0$, the Cholesky decomposition is then used which imposes a lower triangular matrix. Since the main purpose of this paper is to identify the impacts of an external policy from the US to the local macroeconomic variables of India, the introduction of a short-run restriction which follows a country-based exogenous approach. The ordering of the variables in the vector as in (2) is very important when using the Cholesky decomposition. Furthermore, it assumes that the shocks in the system can only influence the uncertainty measures with a lag. Colombo (2013) follows a study by Favero and Giavazzi (2013) in assuming that the uncertainty shocks which hit the euro area exert no contemporaneous effects on the US variables. This is the reason why the US foreign block is ordered before the Indian domestic block in (2). It is evident that both NewsUS and NewsIND are ordered last in the respective blocks. Colombo (2013) states that this is done so that we purge the policy uncertainty index in VAR of contemporaneous changes of macroeconomic variables. This will then improve the identification of the uncertainty shocks. Before running the SVAR, it is important to determine the appropriate lag length to be included in the model: Schwarz's Information Criteria (SC) and the Akaike's Information Criteria (AIC). The optimal number of lags in the model is selected by the combination of an initial lag selection based on both the SC and AIC. The information criteria based on SC suggests a lag of one, whereas AIC suggests a lag of two. Therefore, the results suggest two lags be included in the model. The results are observed to be robust to different lag length choices. An LMF test is performed to observe for No Serial Correlation in the error terms. The SVAR (3) includes an equation with constants and has a linear trend, hence (1).

\section{Empirical Findings}

Figure 1 (Appendix A) shows the Impulse Response Functions (IRF) to a one standard deviation shock to the US uncertainty index. It becomes evident that in India the responses of industrial production and inflation are statistically insignificant following a US uncertainty shock. This suggests a decline in productivity, as well as a stage of deflation after there has been an increase in policy uncertainty. The industrial production hits its lowest value after two months, reaching a minimum approximately $-0.294 \%$, whereas inflation hits its lowest value after three months, reaching its minimum approximately $-0.032 \%$. Figure 1 reports the impulse 
responses to an unanticipated US economic policy uncertainty shock. The columns report the IRFs for the Indian macroeconomic variables. The solid lines show the median IRFs. The red area identifies the $90 \%$ confidence intervals, referred to as the bootstrap-after-bootstrap confidence intervals in (Kilian, 1998). The economic policy uncertainty indices are expressed in levels, whereas the other macroeconomic variables are expressed in percentage form, with respect to their steady states. The horizontal axis identifies the time horizon, expressed in months.

Figure 1: Empirical Impulse Response to a US economic uncertainty shock
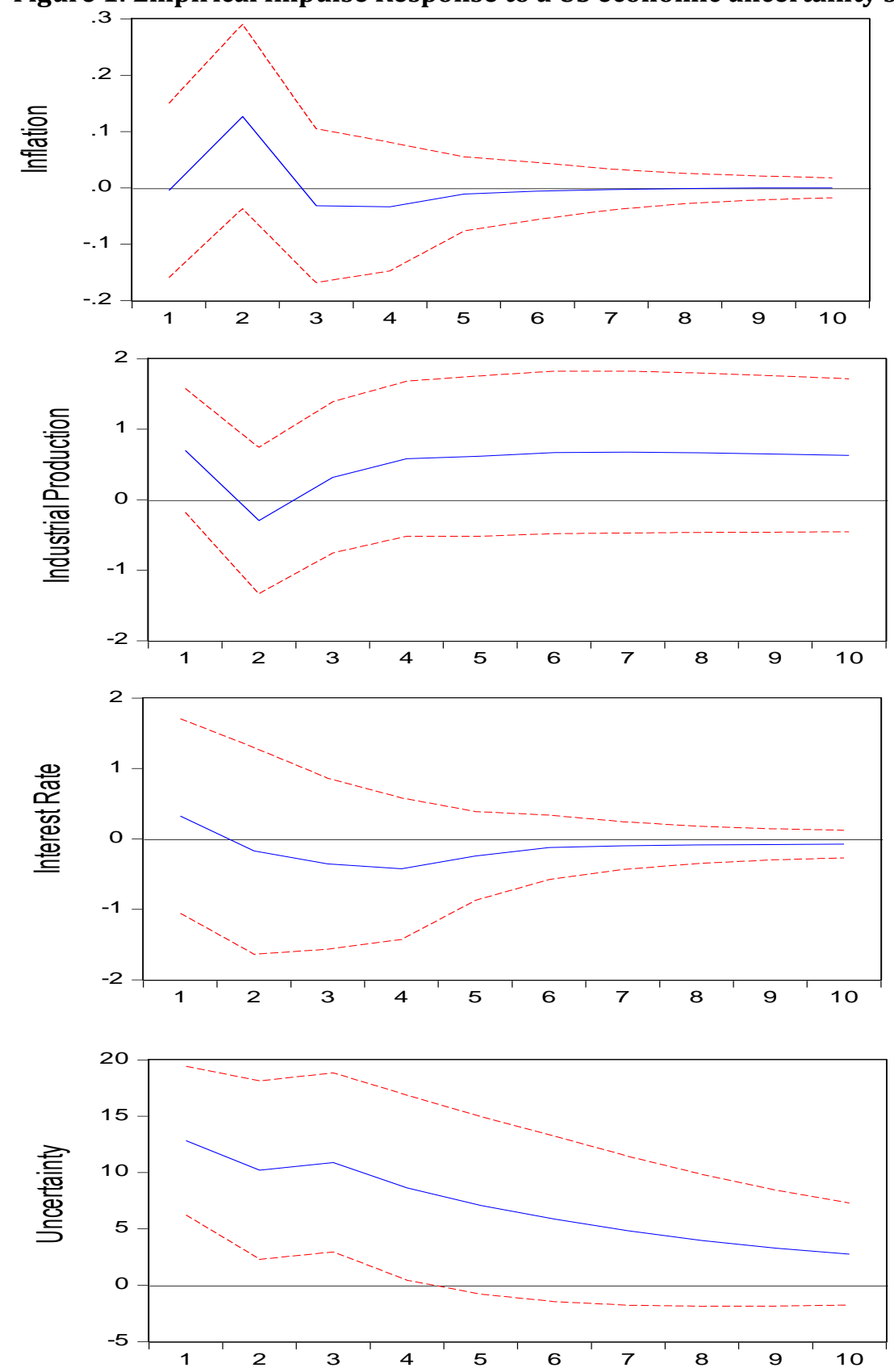

Figure 1 shows that there is a negative reaction of productivity to monetary policy shocks immediately when there is an uncertainty shock. There is a relatively larger reaction observed under high policy uncertainty. One way in which uncertainty decreases the impact of monetary policy shocks on output is that the high level of uncertainty with regards to policy changes will lead to a larger risk premium that firms require from 
projects. This may render these projects to be unprofitable (Balcilar et al., 2016). It is argued that high levels of uncertainty increase the value of the real-option associated with the investment projects (Aastveit et al., 2013; Balcilar et al., 2016). However, the increase in the real-option in periods of high uncertainty will lead to productivity response to monetary policy shocks to be low. It is also observed that an immediate negative reaction of prices to a US uncertainty shock.

The study finds that uncertainty shocks from the US are able to produce significant recessions. Within one month following a high, positive uncertainty shock, industrial production and inflation will fall as well as the level of investments and consumption. These findings are similar to those of Bernanke (1983); Leahy and Whited (1996) and Bloom (2009). The Reserve Bank of India reacts quickly to the economic state by introducing an expansionary monetary policy. When the economy settles on its recovery path, the nominal interest rate will return back to its original level. These results validate those as reported in the previous literature on the type of effects that are stimulated by uncertainty shocks in the euro area: Bloom (2009); Bhaghat et al. (2013); Colombo (2013) and Leduc and Liu (2013). In answering the research question of this paper, it was found that the VARs which was employed predicted an insignificant, negative and sometimes a mild reaction of the Indian macroeconomic variables to an unanticipated increase in the US policy uncertainty. With these results, India proves to be quite immune to policy uncertainty arising from the US. The industrial production drops to $-0.294 \%$ two months after the shock, while inflation drops to $-0.005 \%$ one month after the shock. Then both industrial production and inflation will revert back to their respective preshock levels.

Colombo (2013) explains that increases in uncertainty result in firms postponing investment and households postponing their consumption. This is due to a precautionary saving motive, as well as an increase in the option-value for waiting (Bloom, 2009). The decrease in demand may be accountable for the non-permanent deflation as predicted by the VARs. There is a monetary policy easing which corresponds to a temporary cut in the nominal interest rate which is in line with the inflation targeting strategy which is pursued by the monetary policymakers (Colombo, 2013). Also, Balcilar et al. (2016) observe that a large impact on interest rate in the case of high policy uncertainty may reflect the political risk premium embedded in the short-term rates due to the high level of uncertainty regarding the cost of potential policy changes. Particularly, the impulse responses indicate that policy uncertainty in India increases when there is an exogenous increase in the US policy uncertainty shock. Although, India turns out to be resistant to US policy uncertainty, at the high level of impurities which involve both the US and India at the financial and commercial levels, all the policy decisions and/or indecisions taken at the US are most likely to give rise to the anticipated insecurity encompassing policy changes in India. Certainly, the VARs indicated in this paper do not differentiate between the responses by the Indian macroeconomic variables because of an increase in the US uncertainty shocks as opposed to responses to an increase in the endogenous element of the Indian uncertainty index. Fortunately, according to Colombo (2013), this does not entirely change the main message: the US economic policy uncertainty shocks exert a higher response onthe Indian macroeconomic variables. Given this message, Colombo (2013) poses a question, "How important is a US uncertainty shock?" In answering this question, he uses a forecast error variance decomposition, which was also used to highlight the contribution of US and Indian policy uncertainty shocks to explain the short-run fluctuation in the Indian macroeconomic variables.

In Table 1, the variance decomposition presented indicates that the US uncertainty shocks have a minor effect on inflation, industrial production and the nominal interest rate within a very short period of time. Specifically, at the seventh-month horizon, approximately $5.03 \%$ of the variance in inflation, $0.24 \%$ in industrial production and $0.8 \%$ in nominal interest rate is attributable to the uncertainty shock from the US. It becomes evident from Table 1 that the US policy uncertainty shock illustrates a recognizable share of the variance of the forecast error of India, especially for inflation. Essentially, such a shock appears to be more appropriate for the Indian macroeconomic variables. The stance was taken in this paper that all the actions taken by the US government regarding policy changes in the US are the main source of policy uncertainty for the Indian investors and policymakers. However, high levels of uncertainty that spill over from the US will drive investors to take a wait-and-see approach in their investment decisions as they cannot anticipate how changes in the US economic policy will translate into potential policy change in India. High levels of uncertainty regarding policy changes in the US creates the monetary policy to be less profound in India. This 
is proven by a weak reaction of price and productivity to monetary tightening. The Reserve Bank of India intervenes actively to mitigate the negative effects uncertainty on the economy of India.

Table 1: US and Indian policy uncertainty shock causing the forecast error variance decomposition of the Indian macroeconomic variables (in \% form)

\begin{tabular}{|c|c|c|c|c|c|c|}
\hline Time Horizon & \multicolumn{2}{|c|}{$C P I^{I N D}$} & \multicolumn{2}{|c|}{$I P I^{I N D}$} & \multicolumn{2}{|c|}{$i^{I N D}$} \\
\hline $\begin{array}{l}\text { (indicated in } \\
\text { months) }\end{array}$ & News ${ }^{U S}$ & $N e w s^{I N D}$ & News ${ }^{U S}$ & $N e w s^{I N D}$ & News ${ }^{U S}$ & $N e w s^{I N D}$ \\
\hline 1 & 1.127 & 0.015 & 1.458 & 0.009 & 0.258 & 0.007 \\
\hline 4 & 4.073 & 3.134 & 0.105 & 0.108 & 0.252 & 0.304 \\
\hline 7 & 5.025 & 4.214 & 0.239 & 0.168 & 0.897 & 0.422 \\
\hline 10 & 5.099 & 4.430 & 0.404 & 0.309 & 0.894 & 0.498 \\
\hline 13 & 5.093 & 4.461 & 0.569 & 0.470 & 0.834 & 0.549 \\
\hline
\end{tabular}

\section{Conclusion and Policy Recommendations}

This study attempted to answer the question: "Are there any effects of economic policy uncertainty on real economic activity? If so, how large is the impact of policy uncertainty shocks?" The evidence found that there is an impact of policy uncertainty. Especially if the evidence represented changes in uncertainty felt by households, investors and firms. To determine the impact of these shocks an estimate series of VAR with a new measure of economic policy uncertainty proxied by newspaper coverage for both the US (NewsUS) and India (NewsIND) was utilized. The evidence found that an unanticipated increase in uncertainty, regardless of the measure, results in a sharp, temporary recession. Furthermore, industrial production, consumption, productivity and investment declined, whereas unemployment was likely to rise. The responses to these shocks were rapid and the recovery time thereof was relatively short. Generally, the patterns suggested a role for models of this kind as presented in Bloom (2009). The responses of investment can assist in discriminating between competing theories of how uncertainty changes investment behavior (Alexopoulos \& Cohen, 2009). The impulse responses have shown that economic policy uncertainty is a very powerful index. The findings on the economic policy uncertainty suggested that other uncertainty shocks should be added such as technology shocks, oil prices and the news shock as a significant contributor to the short-run business cycle fluctuations. As such, future research should focus on identifying which types of uncertainty shocks are most damaging to the economy, and also to create models that clearly capture these shocks. Even when focusing specifically on India as a Euro area country, this papers findings also answer the question posed by Colombo (2013). Specifically, Colombo (2013) asks, "Are there any spillovers from the US economy to the Euro area due to economy policy uncertainty shocks?" But it was proven that the VARs rendered an undesirable, mild and insignificant response of the Indian macroeconomic variables to an unanticipated surge in the US policy uncertainty.

The results found that the impact of the US policy uncertainty shock on the Indian macroeconomic variables has been found to be significantly higher than the impact by the Indian variables. Policymakers should be mindful of the results presented in this paper. The results suggest that any policies or delays in action that increase the level of uncertainty in the economy can be very harmful. Many international companies which were considering India for both their services and manufacturing supply chain, were willing to expand in the country but an unfriendly business environment and high policy uncertainty held them back from investing (Spagnol, 2014). Labor cost remained the most attractive asset, while business investment, Foreign Direct Investment (FDI) regulations and taxation policy are key challenges. This is why, in most cases, investment has been deferred until after the parliamentary election (which was held in 2014) so investors can assess the path of economic policy and reforms under the new government. Once the elections were held, the measures of uncertainty rapidly increased, and were consistent with the empirical results presented in this paper. The most recent statistics reveal that the economy is slipping deeper into a recession. Policymakers should aim at maintaining monetary and financial stability in order to reduce policy uncertainty. 


\section{References}

Aastveit, K., Natvik, G. \& Sola, S. (2013). Economic Uncertainty and the Effectiveness of Monetary Policy. Norges Bank, Working Paper No. 2013/17.

Alexopoulos, M. \& Cohen, J. (2009). Uncertain Times, Uncertain Measures. University of Toronto Department of Economics, Working Paper, 352, Mimeo.

Baker, S., Bloom, N.\& Davis, S. (2013). Measuring Economic Policy Uncertainty. National Bureau of Economic Research, Working Paper 21633.

Balcilar, M., Demirer, R., Gupta, R. \& van Eyden, R. (2016). Effectiveness of Monetary Policy in the Euro area: The role of US Economic Policy Uncertainty. Department of Economics, University of Pretoria, Working Paper 201620.

Bansal, R., Khatchatrian, V. \& Yaron, A. (2005). Interpretable asset markets? European Economic Review, 49, 531-560.

Bar-Ban, A. \& Strange, W. (1996). Investment Lags. American Economic Review, 86(3). Available from: http://www.jstor.org/stable/2118214 Accessed: 21 June 2016

Berlin, D. (2016). Economic effects of uncertainty. Available: https://www.diw.de/en/diw_01.c.530110.en/press/diw_roundup/economic_effects_ofuncertainty.h tmlAccessed: 14 August 2016

Bernanke, B. (1983). Irreversibility, Uncertainty, and Cyclical Investment. Quarterly Journal of Economics, 98(1),85- 106.

Bhagat, S., Ghosh, P. \& Rangan, S. (2013). Economic Policy Uncertainty and Economic Growth in India. Indian Institute of Management Bangalore. Working Paper, 407, 1 - 19.

Bloom, N. (2009). The Impact of Uncertainty Shocks. Econometrica, 77(3),623-685.

Bloom, N. (2013). Has Economic Policy Uncertainty Slowed Down the World Economy? World Development Report 2014. Stanford University.

Colombo, V. (2013). Economic Policy Uncertainty in the US: Does it matter for the Euro area? Economic Letters, 21(1), 39-42.

Doms, M. \& Morin, N. (2004). Consumer sentiment, the economy, and the news media. Working papers in Applied Economic Theory: 2004 - 2009. Federal Reserve Bank of San Francisco.

Ehrmann, M. \& Fratzscher, M. (2009). Global Financial Transmission of Monetary Shocks. Oxford Bulletin of Economics and Statistics, 71(6),739-759.

Favero, C. \& Giavazzi, F. (2008). Should the Euro area be run as a Closed Economy? American Economic Review, 98(2),138-230.

Fernandez-Villaverde, J., Guerron-Quitana, P., Keuster, K. \& Rubio-Ramirez, J. (2012). Fiscal volatility shocks and economic activity. Working paper, Boston University and Federal Research Board.

Friedman, M. (1968). The role of Monetary Policy. American Economic Review,58(1),1 - 17.

Gilchrist, S., Jae, W., Sim, S. \& Zakrajsek, E. (2010). Uncertainty, Financial Friction and Investment Dynamics. Working Paper, Boston University and Federal Research Board.

Higgs, R. (1997). Regime Uncertainty: Why the Great Depression lasted so long and Why Prosperity resumed after the War. The independent Review, 4, 561 - 590.

Julio, B. \& Yook, Y. (2012). Political uncertainty and corporate investment cycles. Journal of Finance, 67(1),45 $-84$.

Kilian, L. (1998). Small sample Confidence Interval for Impulse Response Functions. Review of Economics and Statistics, 80(2),218 - 230.

Kim, S. (2001). International Transmission of US Monetary Policy Shocks: Evidence from VARs. Journal of Monetary Economics, 48(2),339 - 372.

Leduc, S. \&Liu, Z. (2013). Uncertainty shocks are Aggregate Demand Shock. Federal Reserve Bank of San Francisco, Mimeo.

Leahy, J. \& Leahy, T. (1996). The Effect of Uncertainty on Investment: Some Stylized Facts. Journal of Money, Credit and Banking, 28(1),64 - 83.

Mumtaz, H. \& Zanetti, F. (2012). The Impact of the Volatility of Monetary Policy Shocks. Journal of Money, Credit and Banking, 45(4),535 - 558.

Pfaff, B. (2008). VAR, SVAR, and SVEC Models: Implementation within R Package VARS. Kroberg in Taurus.

Ramey, S., Valrie, A.\& Shapiro, M. (2001). Displaced Capital: A study of Aerospace Plant Closings. Journal of Political Economy, 109(5). 
Rodrik, D. (1991). Policy Uncertainty and private investment. Journal of Development Economics, 36, 229 242.

Sims, C., Stock, J. \& Watson, M. (1990). Inference in Linear Time Series Models with some Unit Roots. Econometrica, 58(1),113-144.

Spagnol, G. (2014). General elections in India: The World's Largest Democracy. IERI Working Paper6, Bruxelles.

Sum, V. (2012). Economic Policy Uncertainty and Stock Market Returns. University of Marlyland. Eastern Shore.

\section{Appendix A}

Figure 1: Empirical Impulse Response to a US economic uncertainty shock
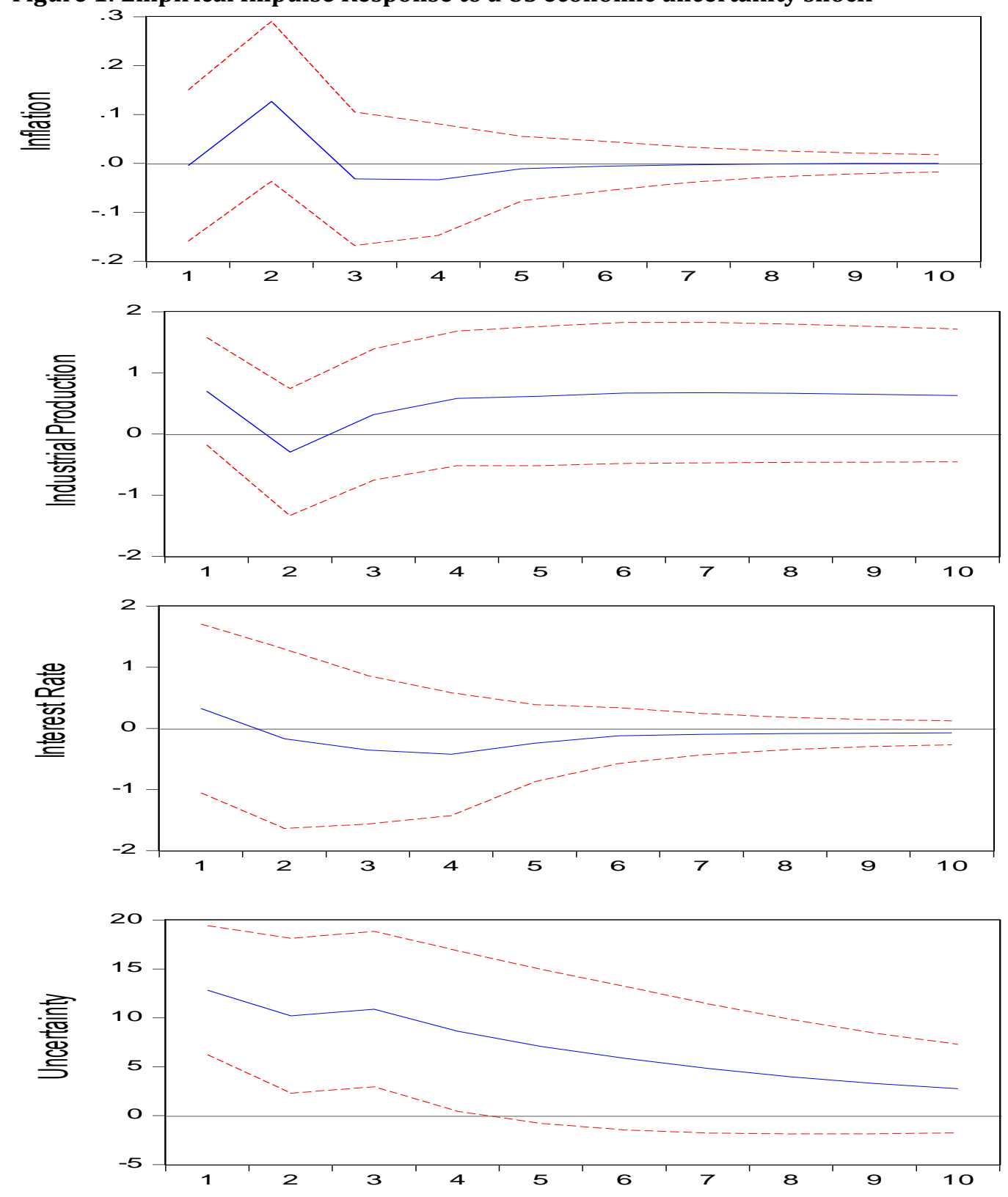